BENTHAM OPEN
CrossMark
Content list available at: www.benthamopen.com/TOOPHTJ/ The Opent
DOI: $10.2174 / 1874364101812010264,2018,12,264-272$

RESEARCH ARTICLE

\title{
Refractive Error among Male Primary School Students in Jazan, Saudi Arabia: Prevalence and Associated Factors
}

Tariq Al Bahhawi ${ }^{1}$, Anwar M Makeen ${ }^{1}$, Hadi Hassan Daghreeri', Mohannad Faisal Tobaigy ${ }^{2}$, Abdulrahman Mohammed Adawi², Faisal Mohammed Guhal ${ }^{2}$, Murad Abdullah Akkur ${ }^{2}$, Mohsen Jaber Alotayfi $^{2}$, Mutaz Mohammed Otayf ${ }^{2}$, Meshal Salem Bajoned ${ }^{2}$ and Mohamed Salih Mahfouz ${ }^{*}, 1$

${ }^{I}$ Department of Community Medicine, Faculty of Medicine, Jazan University, Jazan, Kingdom of Saudi Arabia

${ }^{2}$ Faculty of Medicine, Jazan University, Jazan, Kingdom of Saudi Arabia

Received: June 20, 2018

Revised: August 25, 2018

Accepted: September 10, 2018

Abstract:

Background:

Refractive error is a common and serious eye disorder that affects more than 153 million people globally. The aim of this study was to estimate the prevalence and pattern of refractive error among male primary school children in Jazan region, Saudi Arabia.

\section{Methods:}

A cross-sectional study was conducted among a randomly selected group of 395 students (aged 6-14 years) in Jazan region, Southwest Saudi Arabia. An optometrist and medical students assessed the refraction error using an autorefractor, a Snellen E chart and retinoscopy.

Results:

The overall prevalence of uncorrected refractive error in either eye was, $22 \%$ higher among rural students. The most prevalent refractive error was hyperopia (32.2\%) followed by myopic astigmatism (31\%) then myopia (17.2\%). Next were hyperopic astigmatism (16.1\%) and mixed astigmatism (3.5\%). The following variables were associated with a higher risk of refractive errors and myopia: living in rural areas, having parents with refractive errors, spending more time on electronic devices and shorter visual distances.

\section{Conclusion:}

Refractive error was highly prevalent among primary school children in Jazan, Saudi Arabia. The rural students were more affected by refractive errors, mainly hyperopia. The preschool vision test should be reconsidered, and a periodic vision examination should be applied to detect vision problems as early as possible.

Keywords: Refractive Error, Myopia, Hyperopia, Jazan region, Prevalence and associated factors, Optometrist.

\section{INTRODUCTION}

The WHO has estimated that about 153 million people over the age of five years are visually impaired as a result of uncorrected Refractive Error (RE) [1]. Around 12.8 million children (aged 5 to 15 years) are visually impaired, with a global prevalence of $1 \%$, due to uncorrected or inadequately corrected refractive errors [1].

\footnotetext{
"Address correspondence to this author at the Department of Community Medicine, Faculty of Medicine, Jazan University, Jazan, Kingdom of Saudi Arabia; E-mail: mm.mahfouz@gmail.com
} 
The WHO and 20 international Non-Governmental Organizations (NGOs) launched the global initiative, "Vision 2020 ," in 1999 with the aim of eliminating avoidable blindness by the year 2020 [2].

Visual impairment due to uncorrected refractive errors can lead to short-term and long-term consequences in adults and children. Examples include lost educational and career opportunities lost economic benefits for individuals, families and societies, and poor quality of life [1,3]. Moreover, the uncorrected refractive error could decrease a child's interaction and learning in the classroom, negatively affecting his or her learning process [4].

In Saudi Arabia, many studies have been conducted to estimate the prevalence and pattern of refractive error among primary school children. A study conducted in Abha city revealed an RE prevalence of $23 \%$, while one conducted on pre-school children in Jeddah city showed an RE prevalence of $10.7 \%[5,6]$. Desouky and Tariq-Khan (2014) conducted a study in Taif City that showed a 16.4\% RE prevalence in a sample of female primary school children [7]. Moreover, Wadaani et al. (2013) conducted a study on primary school children in Al Hassa region that revealed a RE prevalence of $13.7 \%$ [8].

Although many studies have been conducted on refractive error in Saudi school children, a literature search suggested that no previous study had been conducted to measure the prevalence of refractive errors among children in Jazan region. Hence, the aim of the present study was to estimate the prevalence and pattern of refractive error among primary school children in Jazan region, Saudi Arabia.

\section{METHODS}

\subsection{Design and Setting}

A cross-sectional study was conducted among male primary school students (age range: 6-14 years) in Jazan region in October 2015. Jazan region is one of the smallest regions in Saudi Arabia; it is located in Southwest Saudi Arabia and stretches along the Red Sea coast for $300 \mathrm{~km}$, immediately north of Yemen. The total population of the region was about $1,500,000$ in the year 2015 [9].

\subsection{Sampling Procedure}

The sample size for this study was determined to be 500 students based on a sample size formula for a crosssectional study design [10]. The following parameters were used for sample size estimation: $p=50 \%$, 95\% Confidence Interval (C.I.), an error below 5\% and a non-response rate of $10 \%$. The proposed sampling design was a multistage sampling method that divided Jazan region into two educational sections-the Jazan and Sabya general educational departments. The Jazan general educational department was randomly selected. Then it was divided into six educational centers based on Ministry of Education segmentation. Two primary schools from each educational sector were randomly selected then lists of children at each school were used as sample frames for the simple random sampling method.

\subsection{Demographics and Vision Data}

For other demographic and risk factor information, a short questionnaire was designed, and parents or guardians responded to it. The questionnaire sought information on details such as the child's personal data, father's and mother's levels of education, family income, internet use, watching television (TV), playing computer games and family history of RE.

\subsection{Refractive Error Examinations}

The examinations conducted involved three main steps: first was the examination of visual acuity using a Snellen C chart. Next was the autorefractor test (ACCUREF R-800) to measure the spherical equivalent and the cylindrical equivalent. Last was the non-cycloplegic retinoscopic examination by a trained optometrist.

\subsection{Snellen Chart and Autorefractometer}

All the children underwent full uncorrected visual acuity assessment. Each child was positioned 6 meters away from a well-lit $\mathrm{C}$ chart. The child's right eye was examined while the left eye was covered, and vice versa. Then the child was instructed to identify the optotype on the monitor. The smallest line on which the child could read more than half of the letters was recorded. The autorefractor examination was done by placing each child's chin on the chin holder and asking him to view the image with both eyes. 


\subsection{Non-Cycloplegic Retinoscopy}

The optometrist used a streak retinoscope to confirm the results. The children's spherical equivalent (SE) was considered as the mean and the SE calculated using the standard formula (SE = sphere + (cylinder/2)). The definitions of refractive error were based on the following categories: myopia $\leq-0.75$ diopters (D), low myopia $\leq-0.75 \mathrm{D}$ to $\geq-3$ $\mathrm{D}$, moderate myopia $\leq-3 \mathrm{D}$ to $\geq-6 \mathrm{D}$, high myopia $\leq-6 \mathrm{D}$, hyperopia $\geq 1 \mathrm{D}$, high hyperopia $\geq 3 \mathrm{D}$ and astigmatism $\geq 1 \mathrm{D}$ [11].

\subsection{Data Analysis}

Data was entered and analyzed using SPSS version 20 (SPSS Inc., Chicago, IL, USA). Data analysis involved descriptive statistics as well as some techniques of inferential statistics. The descriptive statistics included a simple tabulation, frequencies and cross-tabulations. The chi-squared test was used to test differences in proportion and Odds Ratios (ORs), and their 95\% Confidence Intervals (CIs) were used as indicators of strength of association. A $p$-value of less than 0.05 was used as the cut-off level for statistical significance.

\section{RESULTS}

The informed consent form and the study questionnaire were distributed to 500 students in all the selected governorates. A total of 395 (79\%) requests for consent received approval: the parents of the students signed them. The demographic characteristics of the students are presented in Table 1. According to the table, the students' ages ranged from 6-14 years, and rural students represented $70.1 \%$ of the total number of students.

Table 1. Demographic characteristics of the study population $(n=395)$.

\begin{tabular}{|c|c|c|}
\hline Characteristic & $\mathbf{N}$ & $\%$ \\
\hline Place of residence $(n=388)$ & - & - \\
\hline Rural & 272 & 70.1 \\
\hline Urban & 116 & 29.9 \\
\hline $\begin{array}{c}\text { Age group (years) } \\
(n=385)\end{array}$ & - & - \\
\hline $6-8$ & 130 & 33.8 \\
\hline $9-11$ & 204 & 53 \\
\hline $12-14$ & 51 & 13.2 \\
\hline Mother's level of education $(n=390)$ & - & - \\
\hline Illiterate & 68 & 17.4 \\
\hline Basic education & 200 & 51.3 \\
\hline University and above & 122 & 31.3 \\
\hline Father's level of education $(n=392)$ & - & - \\
\hline Illiterate & 31 & 7.9 \\
\hline Basic education & 227 & 57.8 \\
\hline University and above & 134 & 34.2 \\
\hline Monthly income (SAR) (n=372) & - & - \\
\hline Less than 5,000 & 115 & 30.9 \\
\hline $5,000-10,000$ & 106 & 28.5 \\
\hline More than 10,000 & 151 & 40.6 \\
\hline Classes $(n=389)$ & - & - \\
\hline First & 56 & 14.4 \\
\hline Second & 56 & 14.4 \\
\hline Third & 74 & 19 \\
\hline Fourth & 78 & 20.1 \\
\hline Fifth & 63 & 16.2 \\
\hline Sixth & 62 & 15.9 \\
\hline
\end{tabular}

The total number of students with refractive errors was $n=87$, with a prevalence of $22 \%(95 \%$ CI 18.2-26.4). The percentage of affected students in rural areas was $24.6 \%$ (95\% CI 19.9-30.1) compared to $15.5 \%$ (95\% CI 10.1-23.2) in urban areas; a significant difference existed between them $(p$-value $=0.047)$. The rest of the data in the table did not 
show significant differences where the different characteristics were concerned as the $p$-values were higher than 0.05 . We found that refractive errors affected both eyes at a percentage of $89 \%$, while they affected the right eye alone at a rate of $7 \%$ and the left eye alone at a rate of $4 \%$ (Table 2 ).

Table 2. Prevalence of refractive error with regard to some selected characteristics.

\begin{tabular}{|c|c|c|c|}
\hline \multirow{2}{*}{ Characteristic } & \multicolumn{2}{|c|}{ Students with RE } & \multirow{2}{*}{$p$-value* } \\
\hline & $\mathbf{N}(\%)$ & $95 \% \mathrm{CI}$ & \\
\hline Overall Prevalence & $87(22.0)$ & $(18.2-26.4)$ & - \\
\hline Place of residence & - & - & \multirow[t]{3}{*}{0.047} \\
\hline Rural & $67(24.6)$ & $(19.9-30.1)$ & \\
\hline Urban & $18(15.5)$ & $(10.1-23.2)$ & \\
\hline Age group (years) & - & - & \multirow[t]{4}{*}{0.640} \\
\hline $6-8$ & $31(23.8)$ & $(17.4-31.9)$ & \\
\hline $9-11$ & $43(21.1)$ & $(16.1-27.2)$ & \\
\hline $12-14$ & $9(17.6)$ & $(9.6-30.3)$ & \\
\hline Mother's education status & - & - & \multirow[t]{4}{*}{0.168} \\
\hline Illiterate & $7(10.3)$ & $(5.1-19.8)$ & \\
\hline Basic education & $46(23)$ & $(17.7-29.3)$ & \\
\hline University and above & $31(25.4)$ & $(18.5-33.8)$ & \\
\hline Father's education status & - & - & \multirow[t]{4}{*}{0.316} \\
\hline Illiterate & $6(19.4)$ & $(9.3-36.4)$ & \\
\hline Basic education & $45(19.8)$ & $(15.2-25.5)$ & \\
\hline University and above & $34(25.4)$ & $(18.8-33.4)$ & \\
\hline Monthly income (SAR) & - & - & \multirow[t]{4}{*}{0.389} \\
\hline Less than 5,000 & $20(17.4)$ & $(11.6-25.4)$ & \\
\hline $5,000-10,000$ & $28(26.4)$ & $(19-35.6)$ & \\
\hline More than 10,000 & $36(23.8)$ & $(17.8-31.3)$ & \\
\hline Grades & - & - & \multirow[t]{7}{*}{0.737} \\
\hline First & $15(26.8)$ & $(17-39.7)$ & \\
\hline Second & $12(21.4)$ & $(12.7-33.9)$ & \\
\hline Third & $12(16.2)$ & $(9.6-26.3)$ & \\
\hline Fourth & $16(20.5)$ & $(13.1-30.8)$ & \\
\hline Fifth & $16(25.4)$ & $(16.3-37.4)$ & \\
\hline Sixth & $13(21)$ & $(12.7-32.7)$ & \\
\hline
\end{tabular}

- Based on chi-squared test

Table 3 presents the prevalence of myopia, hyperopia and myopic and hyperopic astigmatism with demographic characteristics. Among students with refractive error, hyperopia was the most common refractive error in the sample (32.2\%) followed by myopic astigmatism (31\%) then myopia (17.2\%). Hyperopic astigmatism (16.1\%) and mixed astigmatism (3.4\%) followed.

Table 3. Prevalence of myopia, hyperopia and myopic and hyperopic astigmatism with demographic variables.

\begin{tabular}{|c|c|c|c|c|c|c|}
\hline Variables & Myopia NO (\%) & Hyperopia NO (\%) & \begin{tabular}{|c|} 
Myopic AST \\
NO (\%)
\end{tabular} & Hyper. AST NO (\%) & $\begin{array}{c}\text { MIX. AST NO } \\
(\%) \\
\end{array}$ & $p$-value \\
\hline Age Group (years) $(n=83)$ & - & - & - & - & - & \multirow{4}{*}{0.963} \\
\hline $6-8$ & $4(12.9)$ & $10(23.3)$ & $9(29.0)$ & $6(19.4)$ & $2(6.2)$ & \\
\hline $9-11$ & $9(20.9)$ & $14(32.6)$ & $13(30.2)$ & $6(14.0)$ & $1(2.3)$ & \\
\hline $12-14$ & $2(22.2)$ & $3(33.3)$ & $3(33.3)$ & $1(11.1)$ & $0(0.0)$ & \\
\hline Place of Residence $(n=86)$ & - & - & - & - & - & \multirow{3}{*}{0.082} \\
\hline Rural & $15(22.4)$ & $21(31.3)$ & $20(29.9)$ & $10(14.9)$ & $1(1.5)$ & \\
\hline Urban & $0(0.0)$ & $6(31.6)$ & $7(36.8)$ & $4(21.1)$ & $2(10.5)$ & \\
\hline
\end{tabular}


(Table 3) contd.....

\begin{tabular}{|c|c|c|c|c|c|c|}
\hline Variables & Myopia NO (\%) & Hyperopia NO (\%) & $\begin{array}{c}\text { Myopic AST } \\
\text { NO }(\%) \\
\end{array}$ & Hyper. AST NO (\%) & $\begin{array}{c}\text { MIX. AST NO } \\
(\%)\end{array}$ & $p$-value \\
\hline Classes $(n=83)$ & - & - & - & - & - & \multirow{7}{*}{0.485} \\
\hline First & $2(13.3)$ & $5(33.3)$ & $5(33.3)$ & $1(6.7)$ & $2(13.3)$ & \\
\hline Second & $1(8.3)$ & $5(41.7)$ & $4(33.3)$ & $2(16.7)$ & $0(0.0)$ & \\
\hline Third & $0(0.0)$ & $4(33.3)$ & $4(33.3)$ & $4(33.3)$ & $0(0.0)$ & \\
\hline Fourth & $6(37.5)$ & $6(37.5)$ & $3(18.8)$ & $1(6.3)$ & $0(0.0)$ & \\
\hline Fifth & $2(12.5)$ & $5(31.3)$ & $6(37.5)$ & $2(12.5)$ & $1(6.3)$ & \\
\hline Sixth & $3(25.0)$ & $3(25.0)$ & $4(33.3)$ & $2(16.7)$ & $0(0.0)$ & \\
\hline Mother's Education Status $(n=84)$ & - & - & - & - & - & \multirow{4}{*}{0.295} \\
\hline Illiterate & $1(14.3)$ & $3(42.9)$ & $2(28.6)$ & $0(0.0)$ & $1(14.3)$ & \\
\hline Basic Education & $6(13.0)$ & $16(34.8)$ & $14(30.4)$ & $9(19.6)$ & $1(2.2)$ & \\
\hline University \& above & $8(25.8)$ & $9(29.0)$ & $11(35.5)$ & $3(9.7)$ & $0(0.00$ & \\
\hline Father's Education Status $(\mathbf{n}=\mathbf{8 5})$ & - & - & - & - & - & \multirow{4}{*}{0.285} \\
\hline Illiterate & $1(16.7)$ & $2(33.3)$ & $1(16.7)$ & $1(16.7)$ & $1(16.7)$ & \\
\hline Basic Education & $6(13.3)$ & $19(42.2)$ & $11(24.4)$ & $8(17.8)$ & $1(2.2)$ & \\
\hline University \& above & $8(23.5)$ & $7(20.6)$ & $14(41.2)$ & $4(11.8)$ & $1(2.9)$ & \\
\hline Monthly Income (SAR) $(n=85)$ & - & - & - & - & - & \multirow{4}{*}{0.191} \\
\hline Less than 5,000 & $3(14.3)$ & $5(23.8)$ & $11(52.4)$ & $1(4.8)$ & $1(4.8)$ & \\
\hline $5,000-10,000$ & $4(14.3)$ & $12(42.9)$ & $5(17.9)$ & $7(25.0)$ & $0(0.0)$ & \\
\hline$>10,000$ & $8(22.2)$ & $11(30.6)$ & $10(27.8)$ & $6(16.7)$ & $1(2.8)$ & \\
\hline Overall Prevalence & $15(17.2)$ & $28(32.2)$ & 27(31.0) & $14(16.1)$ & $3(3.4)$ & \\
\hline
\end{tabular}

Table 4 illustrates the association between refractive errors and certain risk factors. A positive association with the presence of refractive errors was observed among children who spent more hours watching TV and among students who used electronic devices. Regarding family history of refractive errors, the results showed a significant positive association between children's refractive errors and the status of parents' vision problems with an odds ratio of 1.71 . There was an association between students watching TV from a close distance and refractive error with an odds ratio of less than one for large distances from the TV as large distances decreased the odds of refractive error. The students in the rural areas were significantly more than twice as likely to be affected by refractive errors as the students in the urban areas. The table also indicated that the same factors associated with the refractive errors showed similar relationships with myopia.

Table 4. Association between refractive errors and certain risk factors.

\begin{tabular}{|c|c|c|c|c|c|c|}
\hline \multirow{3}{*}{ Risk Factor } & \multicolumn{3}{|c|}{ Refractive Errors } & \multicolumn{3}{|c|}{ Myopia } \\
\hline & \multirow{2}{*}{ OR } & \multicolumn{2}{|c|}{$(95 \% \mathrm{CI})$} & \multirow{2}{*}{ OR } & \multicolumn{2}{|c|}{$(95 \% \mathrm{CI})$} \\
\hline & & Lower & Upper & & Lower & Upper \\
\hline Age Groups (years) & - & - & - & - & - & - \\
\hline $6-8$ & 1.00 & - & - & 1.00 & - & - \\
\hline $9-11$ & 1.12 & 0.69 & 1.81 & 0.93 & 0.50 & 1.75 \\
\hline $12-14$ & 1.44 & 0.69 & 3.05 & 1.21 & 0.45 & 3.23 \\
\hline Mode of Living & - & - & - & - & - & - \\
\hline Urban & 1.00 & - & - & 1.00 & - & - \\
\hline Rural & 2.70 & 1.55 & 4.68 & 3.93 & 1.63 & 9.46 \\
\hline Use of Electronic Devices (ED) & - & - & - & - & - & - \\
\hline Non-users & 1.00 & - & - & 1.00 & - & - \\
\hline Users & 1.40 & 0.75 & 2.61 & 2.71 & 0.94 & 7.78 \\
\hline Hours Using Elect. Devices & - & - & - & - & - & - \\
\hline Less than 2 Hours & 1.00 & - & - & 1.00 & - & - \\
\hline 3-5 Hours & 2.66 & 0.90 & 7.86 & 3.46 & 1.10 & 10.90 \\
\hline More than 5 Hours & 1.88 & 0.56 & 6.29 & 3.10 & 0.80 & 12.03 \\
\hline Outdoor Activities & - & - & - & - & - & - \\
\hline Yes & 1.00 & - & - & - & - & - \\
\hline $\mathrm{NO}$ & 1.42 & 0.75 & 2.69 & 1.88 & 0.65 & 5.46 \\
\hline
\end{tabular}




\begin{tabular}{|c|c|c|c|c|c|c|}
\hline \multirow{3}{*}{ Risk Factor } & \multicolumn{3}{|c|}{ Refractive Errors } & \multicolumn{3}{|c|}{ Myopia } \\
\hline & \multirow{2}{*}{ OR } & \multicolumn{2}{|c|}{$(95 \% \mathrm{CI})$} & \multirow{2}{*}{ OR } & \multicolumn{2}{|c|}{$(95 \%$ CI $)$} \\
\hline & & Lower & Upper & & Lower & Upper \\
\hline Family History of RE & - & - & - & - & - & - \\
\hline No & 1.00 & - & - & 1.00 & - & - \\
\hline Yes & 1.71 & 1.09 & 2.67 & 2.92 & 1.55 & 5.48 \\
\hline Distance to TV Screen & - & - & - & - & - & - \\
\hline Close & 1.00 & - & - & 1.00 & - & - \\
\hline Average & 0.56 & 0.24 & 1.28 & 0.59 & 0.21 & 1.68 \\
\hline Far & 0.48 & 0.22 & 1.04 & 0.72 & 0.27 & 1.96 \\
\hline
\end{tabular}

\section{DISCUSSION}

Refractive error is a major challenge facing primary school children in Saudi Arabia [5 - 8] and globally [12 - 15] as many children may not know that they have visual problems and may think that they have normal sight. Some students may have trouble reading the board or seeing close objects clearly, which might affect their academic performance and their quality of life.

To the best of our knowledge, this is the first study to address the issue of prevalence and factors associated with Refractive Error (RE) among school children in the Jazan region. The present study revealed the overall prevalence of refractive errors in either eye of $22 \%$, which was very close to $23 \%$, the prevalence that the study conducted in Abha city arrived at [5]. This prevalence is higher than those that other studies conducted in Saudi Arabia (in Al Hassa, Jeddah and Taif City) arrived at $[8,6,7]$.

Upon the comparison of our estimates with those of other studies, we found them to be similar to those of a study conducted in Egypt (22.1\%) [14] and higher than those of studies conducted in countries like Qatar (19.7\%) [16], Nepal (8.6\%) [17] and India (13.09\%) [18]. Our prevalence was also lower than Taiwan's and Srinagar's [19, 20]. The variation in prevalence may have resulted because we conducted this study on a male population only. By contrast, other studies were conducted on both sexes.

Despite the fact that myopia is the most prevalent refractive error globally, our results showed that hyperopia was the most prevalent refractive error in our sample [1]. Moreover, most studies conducted in Saudi Arabia showed that myopia was the most prevalent refractive error [8,21]. A recent study conducted in Jazan supported our findings, which revealed that hyperopia was more prevalent than myopia [22].

Our results showed that hyperopia was the most common refractive error $(32.2 \%)$ of all, followed by myopic astigmatism (31\%), myopia (17.2\%), hyperopic astigmatism (16.1\%) and mixed astigmatism (3.5\%). On the other hand, the study that Waddani et al. (2013) conducted in Al Hassa [8] found the most prevalent refractive error to be myopia $(65.6 \%)$ followed by myopic astigmatism $(12.4 \%)$, hyperopic astigmatism $(12 \%)$ and hyperopia $(9.8 \%)$. The differences could be attributed to the differentials in socioeconomic conditions, variations in the operational definitions, cut-off points of refractive errors and factors related to environmental influences.

In contrast to many studies [23 - 25], our results showed that refractive errors affected the rural population more than the urban population. Regarding the associations between refractive errors and selected risk factors, the data of our study support the findings of other studies. We found an association between refractive errors and parental history of refractive errors that was in line with the findings of Ip et al. (2007) and Zadnik et al. (1994) [26, 27]. We also found an association between time spent on electronic devices and refractive errors, and this was well documented by [28, 29]. Moreover, shorter distances from the TV screen were emphasized by [26, 29], and our results revealed an association between short distances from the TV screen and the increased risk of refractive errors and myopia.

The lack of cycloplegic objective refraction was a major limitation of this study. We should be very careful when interpreting the results of this study, for cycloplegia is truly the gold standard for the diagnosis of refractive errors. It is regrettable that such a procedure was not performed. The reason for this failure was that the procedure would have blurred the students' vision for 3-8 hours. The intrinsic value of this study would have increased immensely had cycloplegic drops been used for a reliable objective refraction. Secondly, we conducted our study on male students alone for some practical reasons. Finally, the study was based on a cross-sectional study design, so the risk factors should be interpreted carefully. 


\section{CONCLUSION}

Refractive error was highly prevalent among primary school children in Jazan, Saudi Arabia. The rural students were more affected by refractive errors, mainly hyperopia. We recommend a study with cycloplegic to assess the issue of RE in greater depth. The preschool vision test should be reconsidered, and a periodic vision examination should be applied to detect vision problems as early as possible.

\section{AUTHOR CONTRIBUTIONS}

Hadi Hassan Daghreeri, Al-Mohannad Tobaigy, Abdulrahman Adawi, Faisal Gohal, Muraad Akour, Mohsen Otifi, Moataz Otaif and Mishaal Bajonaid conceptualized and designed the study, conducted data collection and wrote the report. Tariq Bahawi and Anwar M. Makeen supervised the work, carried out the initial analysis, reviewed and revised the manuscript, and approved the final manuscript as submitted. Mohamed Mahfouz drafted the manuscript and reviewed and revised it. The entire study team approved the final version of the manuscript as submitted.

\section{ETHICAL APPROVAL AND CONSENT TO PARTICIPATE}

Ethical approval was obtained from the College of Medicine, Jazan University for this study.

\section{HUMAN AND ANIMAL RIGHTS}

No animals were used in this research. All research procedures followed were in accordance with the ethical standards of the committee responsible for human experimentation (institutional and national), and with the Helsinki Declaration of 1975 , as revised in 2008 .

\section{CONSENT FOR PUBLICATION}

The children were told that they had the right not to participate in the study. Moreover, the participants' privacy was respected, and the data were kept confidential and were utilized for study purposes only. The children's parents or guardians were asked to read and sign consent forms before the data collection.

\section{CONFLICTS OF INTEREST}

The authors declare no conflict of interest, financial or otherwise.

\section{ACKNOWLEDGMENTS}

We would like to thank the Future Scientist Program - Deanship of Scientific Research - Jazan University for financially supporting this study. We are also highly indebted to the study participants, who sacrificed their time and participated actively in the study. WE thank Dr. Syed Shafat Ahmed for his support too.

\section{REFERENCES}

[1] Pascolini D, Mariotti SP. Global estimates of visual impairment: 2010. Br J Ophthalmol 2012; 96(5): 614-8. [http://dx.doi.org/10.1136/bjophthalmol-2011-300539] [PMID: 22133988]

[2] Pizzarello L, Abiose A, Ffytche T, et al. VISION 2020: The right to sight: A global initiative to eliminate avoidable blindness. Arch Ophthalmol 2004; 122(4): 615-20. [http://dx.doi.org/10.1001/archopht.122.4.615] [PMID: 15078680]

[3] Fricke TR, Holden BA, Wilson DA, et al. Global cost of correcting vision impairment from uncorrected refractive error. Bull World Health Organ 2012; 90(10): 728-38. [http://dx.doi.org/10.2471/BLT.12.104034] [PMID: 23109740]

[4] Negrel AD, Maul E, Pokharel GP, Zhao J, Ellwein LB. Refractive error study in children: Sampling and measurement methods for a multicountry survey. Am J Ophthalmol 2000; 129(4): 421-6. 
[http://dx.doi.org/10.1016/S0002-9394(99)00455-9] [PMID: 10764848]

[5] Abolfotouh M, Faheem Y, Badawi I, Khairallah S. Prevalence of refractive errors and their optical correction among schoolboys in Abha City, Asir Region, Saudi Arabia. Health Ser J Eastern Mediterran 1993; 7: 2.

[6] Wedad M. Bardisi, Bakr M., bin Sadiq, Vision screening of preschool children in Jeddah, Saudi Arabia. Saudi Med J 2002; 23 (4): 44-449. [PMID: 11938363]

[7] Desouky DE, Nighat M, Tariq K. Refractive error among a sample of female primary school children in Taif City, KSA. Inter J of Public Health and Epidemiol 2014; 2(10): 89-97.

[8] Al Wadaani FA, Amin TT, Ali A, Khan AR. Prevalence and pattern of refractive errors among primary school children in Al Hassa, Saudi Arabia. Glob J Health Sci 2012; 5(1): 125-34. [http://dx.doi.org/10.5539/gjhs.v5n1p125] [PMID: 23283044]

[9] General Authority of Statistics, KSA; Statistical Year Book 2015; Issue Number: 51 » Chapter 02 | Population Statistics http://www.stats.gov.sa/ en/4250

[10] Lwanga SK, Lemeshow S. Sample size determination in health studies: A practical manual 1991.http://apps.who. int/iris/handle/10665/40062

[11] Williams KM, Verhoeven VJM, Cumberland P, et al. Prevalence of refractive error in Europe: The European Eye Epidemiology (E( $\left(^{3}\right)$ ) Consortium. Eur J Epidemiol 2015; 30(4): 305-15.

[http://dx.doi.org/10.1007/s10654-015-0010-0] [PMID: 25784363]

[12] Sewunet SA, Aredo KK, Gedefew M. Uncorrected refractive error and associated factors among primary school children in Debre Markos District, Northwest Ethiopia. BMC Ophthalmol 2014; 14: 95. [http://dx.doi.org/10.1186/1471-2415-14-95] [PMID: 25070579]

[13] Rahman M, Devi B, Kuli JJ, Gogoi G. A study on the refractive status of school going children aged between 10 to 15 years in Dibrugarh Town, Assam, India. IOSR J Dent Med Sci 2015; 14(2): 27-33.

[14] Saad A, Choudhury AH. Prevalence of refractive error and low vision among school children in Cairo. East Mediterr Health J 2007; 13(3): 575-9. [PMID: 17687830]

[15] Pavithra MB, Maheshwaran R, Rani Sujatha MA. A study on the prevalence of refractive errors among school children of 7-15 years age group in the field practice areas of a medical college in Bangalore. Int J Med Sci Public Health 2013; 2(3): 641-5. [http://dx.doi.org/10.5455/ijmsph.2013.220420131]

[16] Bener A, Al-Mahdi HS. Internet use and television viewing in children and its association with vision loss: A major public health problem. J Public Health Africa 2012; 3(1): e16. [http://dx.doi.org/10.4081/jphia.2012.e16] [PMID: 28299088]

[17] Pokharel A, Pokharel PK, Das H, Adhikari S. The patterns of refractive errors among the school children of rural and urban settings in Nepal. Nepal J Ophthalmol 2010; 2(2): 114-20. [http://dx.doi.org/10.3126/nepjoph.v2i2.3717] [PMID: 21505527]

[18] Singh H, Saini VK, Yadav A, Soni B. Refractive errors in school going children: Data from a school screening survey programme. Natl J Community Med 2013; 4(1): 137-40.

[19] Lin LL, Chen CJ, Hung PT, Ko LS. Nation-wide survey of myopia among schoolchildren in Taiwan, 1986. Acta Ophthalmol Suppl 1988; 185(S185): 29-33. [http://dx.doi.org/10.1111/j.1755-3768.1988.tb02657.x] [PMID: 2853535]

[20] Khan AA, Nasti AR, Dar MA, Lone SA. Prevalence of refractive errors in school children. JK Pract 2005; $12(3)$ : 156-9.

[21] Aldebasi YH. Prevalence of correctable visual impairment in primary school children in Qassim Province, Saudi Arabia. J Optometry 2014; 7(3): 168-76.

[22] Darraj A, Barakat W, Kenani M, et al. Common eye diseases in children in Saudi Arabia (Jazan). Ophthalmology and eye diseases 2016; 8

[23] He M, Zeng J, Liu Y, Xu J, Pokharel GP, Ellwein LB. Refractive error and visual impairment in urban children in southern china. Invest Ophthalmol Vis Sci 2004; 45(3): 793-9. [http://dx.doi.org/10.1167/iovs.03-1051] [PMID: 14985292]

[24] Zhao J, Pan X, Sui R, Munoz SR, Sperduto RD, Ellwein LB. Refractive error study in children: Results from Shunyi district, China. Am J Ophthalmol 2000; 129(4): 427-35. [http://dx.doi.org/10.1016/S0002-9394(99)00452-3] [PMID: 10764849]

[25] Dandona R, Dandona L. Childhood blindness in India: A population based perspective. Br J Ophthalmol 2003; 87(3): $263-5$. [http://dx.doi.org/10.1136/bjo.87.3.263] [PMID: 12598433]

[26] Ip JM, Huynh SC, Robaei D, et al. Ethnic differences in the impact of parental myopia: Findings from a population-based study of 12-yearold Australian children. Invest Ophthalmol Vis Sci 2007; 48(6): 2520-8. [http://dx.doi.org/10.1167/iovs.06-0716] [PMID: 17525179]

[27] Zadnik K, Satariano WA, Mutti DO, Sholtz RI, Adams AJ. The effect of parental history of myopia on children's eye size. JAMA 1994; 271(17): 1323-7. [http://dx.doi.org/10.1001/jama.1994.03510410035029] [PMID: 8158816] 
[28] Mutti DO, Mitchell GL, Moeschberger ML, Jones LA, Zadnik K. Parental myopia, near work, school achievement, and children's refractive error. Invest Ophthalmol Vis Sci 2002;43:3633e40.

[29] Hsu CC, Huang N, Lin PY, et al. Prevalence and risk factors for myopia in second-grade primary school children in Taipei: A populationbased study. J Chin Med Assoc 2016; 79(11): 625-32.

[http://dx.doi.org/10.1016/j.jcma.2016.02.011] [PMID: 27349942]

(C) 2018 Al Bahhawi et al.

This is an open access article distributed under the terms of the Creative Commons Attribution 4.0 International Public License (CC-BY 4.0), a copy of which is available at: (https://creativecommons.org/licenses/by/4.0/legalcode). This license permits unrestricted use, distribution, and reproduction in any medium, provided the original author and source are credited. 